\title{
METHOD DEVELOPMENT AND VALIDATION OF LERCANIDIPINE IN HUMAN PLASMA BY LIQUID CHROMATOGRAPHY TANDEM-MASS SPECTROMETRY
}

\author{
YAHDIANA HARAHAP, NORMA ANDRIYANI, HARMITA
}

Bioavailability and Bioequivalence Laboratory, Faculty of Pharmacy, Universitas Indonesia Email: yahdiana03@yahoo.com

Received: 09 Apr 2018, Revised and Accepted: 24 May 2018

\section{ABSTRACT}

Objective: To obtain an optimum and validated method for analyzing lercanidipine in plasma using Ultra Performance Liquid Chromatography of Tandem Mass Spectrometry (UPLC-MS/MS).

Methods: The separation was carried out using $1.7 \mu \mathrm{m}(2.1 \times 100 \mathrm{~mm})$ Waters Acquity ${ }^{\mathrm{TM}}$ UPLC C18 column, a mobile phase of the $0.1 \%$ formic acidmethanol mixture $(20: 80 \mathrm{v} / \mathrm{v})$ with isocratic elution, $30{ }^{\circ} \mathrm{C}$ column temperature, $0.2 \mathrm{ml} / \mathrm{min}$ flow rate and amlodipine as an internal standard. Mass detection was performed with a positive XBL TQD type Electrospray Ionization (ESI) in Multiple Reaction Monitoring modes. Lercanidipine was detected at $\mathrm{m} / \mathrm{z}$ value of $612.11>280.27$ and amlodipine was detected at $\mathrm{m} / \mathrm{z}$ value $409.1>238.15$. The optimum sample preparation method was a liquid-liquid extraction using $5 \mathrm{ml}$ of n-hexane-ethyl acetate (50:50 v/v), vortex mixed for 3 min, centrifuged at 4000 rpm for 20 min, evaporated with nitrogen at 50 ${ }^{\circ} \mathrm{C}$ for $30 \mathrm{~min}$, and the residue was reconstituted with $100 \mu \mathrm{l}$ of mobile phase.

Results: The method was linear in the range of $0.025-10 \mathrm{ng} / \mathrm{ml}$ with $\mathrm{r} \geq 0.9986$. Accuracy and precis ion within-run and between-run met the requirements with \%diff and \%CV, not exceeding $\pm 15 \%$ and not more than $\pm 20 \%$ for Lower Limit of Quantification (LLOQ) concentration.

Conclusion: It was concluded that the developed method met the requirements of selectivity, carry over, stability, the integrity of dilution, and matrix effects under the Guideline on Bioanalytical Method Validation by the European Medicines Agency in 2011.

Keywords: Lercanidipine, Amlodipine, LC-MS/MS, Liquid-liquid extraction, Validation

(C) 2018 The Authors. Published by Innovare Academic Sciences Pvt Ltd. This is an open access article under the CC BY license (http://creativecommons.org/licenses/by/4.0/) DOI: http://dx.doi.org/10.22159/ijap.2018v10i4.26544

\section{INTRODUCTION}

Lercanidipine is effective for the treatment of patients with mild to moderate hypertension without affecting heart rate [1]. As an antihypertensive derivative of calcium channel blockers used in serious conditions, lercanidipine is included on the bioequivalence test mandatory drug list [2]. Implementation of bioequivalence tests must be using validated bioanalysis methods [3] therefore a reliable, rapid, and highly sensitive bioanalytical measurement technique for plasma drug measurement is required.

Ultra High-Performance Liquid Chromatography (UPLC) is a rapid separation technique with higher chromatographic efficiency than High-Performance Liquid Chromatography (HPLC) [4].

In a previous study, LLOQ was obtained at $0.1 \mathrm{ng} / \mathrm{ml}$ with a solid phase extraction method using UPLC-MS/MS, and $1.66 \mathrm{ng} / \mathrm{ml}$ of $\mathrm{C}_{\max }$ lercanidipine was obtained from healthy subjects [5]. The objective of this research is to obtain an optimum and validated method for analyzing lercanidipine in plasma using Ultra Performance Liquid Chromatography of Tandem Mass Spectrometry (UPLC-MS/MS). Hence this research developed lercanidipine analysis method using UPLC-MS/MS to obtain $0.05 \mathrm{ng} / \mathrm{ml} \mathrm{LLOQ}$, in accordance with the requirements of Guideline on Bioanalytical Method Validation by the European Medicines Agency in 2011 that LLOQ is no more than $5 \%$ Cmax $[6,7]$.

\section{MATERIALS AND METHODS}

\section{Equipment}

Ultra high performance liquid chromatography (Waters Xevo TQD Triple Quadrupole) consisting of Quartenary Solvent Manager (Acquity UPLC H-Class), Sample Manager (Acquity UPLC), Nitrogen generator compressor (PEAK Scientific), UPLC Acquity column BEH C18 (100 mm x $2.1 \mathrm{~mm}$ ) $1.7 \mu \mathrm{m}$, a triple quadrupole (Xevo TQD) mass analyzer with an ionization source (ZsprayTM).

\section{Materials}

Lercanidipine (Hetero Drugs Limited); amlodipine (Dr. Reddy's Laboratories Limited); aquabidest (Ikapharmindo); methanol, acetonitrile; formic acid; ammonium formate; n-hesana; ethyl acetate; and dichloromethane were purchased from Merck; Plasma samples (Indonesian Red Cross).

\section{Stock solution}

$5.0 \mathrm{mg}$ lercanidipine was weighed and dissolved with methanol to obtain a concentration of $1.0 \mathrm{mg} / \mathrm{ml}(1000 \mathrm{ppm}) .5 .0 \mathrm{mg}$ amlodipine as the internal standard was weighed and dissolved with methanol to obtain a concentration of $1.0 \mathrm{mg} / \mathrm{ml}(1000 \mathrm{ppm})$. Dilution was done to obtain a solution with a certain concentration.

optimization of lercanidipine analysis used ultra-high performance liquid chromatography-tandem mass spectrometry

Initial optimization was done on the mass spectrometry. The standard solution of lercanidipine $10.0 \mu \mathrm{g} / \mathrm{ml}$ and amlodipine $10.0 \mu \mathrm{g} / \mathrm{ml}$ each of $1 \mathrm{ml}$ were added to the reservoir. Then the standard solution was dispensed into mass spectrometry. During the standard solution, the measurements of mass spectrometry parameters are the tension in the capillary tube, dissolved gas temperature, dissolved gas flow rate, the flow rate at cone, the voltage at cone, source temperature, ions energy, collision energy, and $\mathrm{m} / \mathrm{z}$ ratio on each compound.

The optimization of chromatographic conditions was conducted by injecting a mixture of $1.0 \mu \mathrm{g} / \mathrm{ml}$ lercanidipine and $1.0 \mu \mathrm{g} / \mathrm{ml}$ of amlodipine into the UPLC-MS/MS system and the chromatographic response was observed. Optimization began with the selection of combination and comparison of the mobile phase, then carried out the optimization of mobile phase and column temperature. The optimization was carried out with $2.0 \mathrm{mmol}$ ammonium formate in water $(\mathrm{pH} \mathrm{2.5}$; formic acid buffer)-acetonitrile (5:95 v/v; 10:90 v/v; 15:85 v/v; 20:80 $\mathrm{v} / \mathrm{v}$; and 30:70 v/v); 0.1\% formic acid-acetonitrile (10:90 v/v; 20:80 v/v; and $30: 70 \mathrm{v} / \mathrm{v}$ ); and $0.1 \%$ formic acid-methanol (5:95 v/v; $10: 90 \mathrm{v} / \mathrm{v}$; $20: 80 \mathrm{v} / \mathrm{v}$; and $30: 70 \mathrm{v} / \mathrm{v}$ ). Variations in the optimization of the flow rate of the mobile phase were $0.2 \mathrm{ml} / \mathrm{min}$ and $0.3 \mathrm{ml} / \mathrm{min}$. The column temperature was optimized at $25^{\circ} \mathrm{C} ; 30^{\circ} \mathrm{C}$; and $40{ }^{\circ} \mathrm{C}$.

\section{Optimization of sample preparation}

In this research, the sample preparation used liquid-liquid extraction. As much as $500 \mu \mathrm{l}$ mixture of lercanidipine in plasma with a certain 
concentration was added with $25 \mu \mathrm{l}$ of the internal standard (100 $\mathrm{ng} / \mathrm{ml}$ ). Then the mixture was extracted with $5 \mathrm{ml}$ of extraction solution with the following variations: $100 \%$ hexane, $100 \%$ ethyl acetate, hexane-ethyl acetate $(50: 50 \mathrm{v} / \mathrm{v})$, and $100 \%$ dichloromethane. The mixture was vortexed, optimized for 1,2 , and $3 \mathrm{~min}$ and centrifugation optimization was performed for 5, 10, 15, and 20 min at $4000 \mathrm{rpm}$. Then the organic phase was separated and evaporated with nitrogen at $50^{\circ} \mathrm{C}$ for $30 \mathrm{~min}$, the residue was reconstituted with $100 \mu \mathrm{l}$ of the mobile phase. Finally, $10 \mu \mathrm{l}$ of the aliquot was injected into the chromatography system.

\section{Validation of lercanidipine in plasma}

The full validation of lercanidipine analysis method in plasma was performed with parameters such as selectivity, carry over, LLOQ the linearity of calibration curve, accuracy and precision, recovery, dilution integrity, matrix effect, and stability.

\section{RESULTS AND DISCUSSION}

Optimization of lercanidipine using liquid chromatographytandem mass spectrometry

Detection of lercanidipine in mass spectrometry using positive ESI ionization of Multiple Reaction Monitoring (MRM) type was performed with several ionization parameters such as a capillary voltage of $3.0 \mathrm{kV}$, desolvation temperature of $250{ }^{\circ} \mathrm{C}$, desolvation of $594 \mathrm{~L} / \mathrm{h}$, flow rate at cone $1 \mathrm{~L} / \mathrm{h}$, voltage at cone $50 \mathrm{~V}$, source temperature of $148^{\circ} \mathrm{C}$. The ion energy was 0.2 and collision energy was $20 \mathrm{~V}$. Lercanidipine was detected at $\mathrm{m} / \mathrm{z}$ ratio $612.18>280.27$ while amlodipine detected at 409.1>238.15. The chromatography condition of lercanidipine analysis was conducted using the column of Acquity UPLC BEH C18 $(100 \mathrm{~mm} x$ $2.1 \mathrm{~mm}$ ); $1.7 \mu \mathrm{m}$; with mobile phase consist of $0.1 \%$ formic acidmethanol $(20: 80 \mathrm{v} / \mathrm{v})$; flow rate of $0.2 \mathrm{ml} / \mathrm{min}$; column temperature was $30^{\circ} \mathrm{C}$; and amlodipine as internal standard.

\section{Optimization of sample preparation}

The optimum sample preparation was obtained by extraction of 500 $\mu \mathrm{L}$ plasma containing lercanidipine and amlodipine with $5 \mathrm{ml}$ of $\mathrm{n}$ hexane-ethyl acetate $(50: 50 \mathrm{v} / \mathrm{v})$, then vortexed for $3 \mathrm{~min}$ and centrifuged for $20 \mathrm{~min}$ at $4000 \mathrm{rpm}$. The organic phase was separated and evaporated with nitrogen gas at $50{ }^{\circ} \mathrm{C}$ for $30 \mathrm{~min}$, then the residue was reconstituted with $100 \mu \mathrm{l}$ of the mobile phase. Afterwards $10 \mu \mathrm{l}$ of the aliquot was injected into the chromatography system.

\section{Selectivity}

The selectivity was performed on LLOQ concentrations and plasma blanks using six different plasma sources. The results show that there was no interference or impurity on the retention time of analyte and internal standard. The chromatogram can be seen in fig. 1 . The chromatogram of lercanidipine in plasma with five level concentrations which was LLOQ, Quality Control Low (QCL), Quality Control Medium (QCM), Quality Control High (QCH), and Upper Limit of Quantification (ULOQ) can be seen in fig. 2.
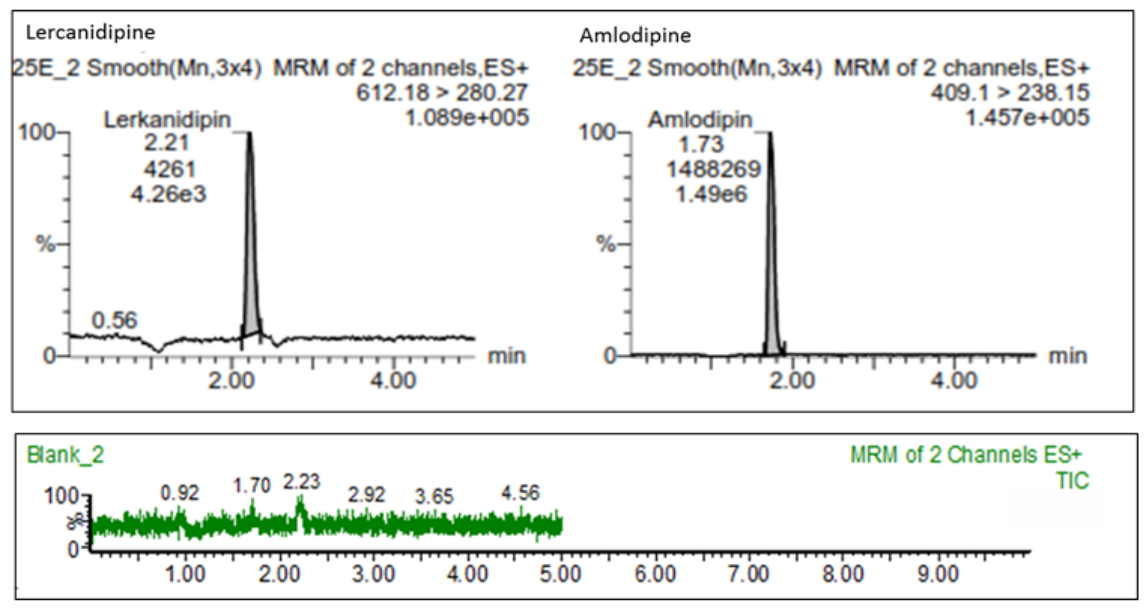

Fig. 1: Lercanidipine chromatogram in blank plasma
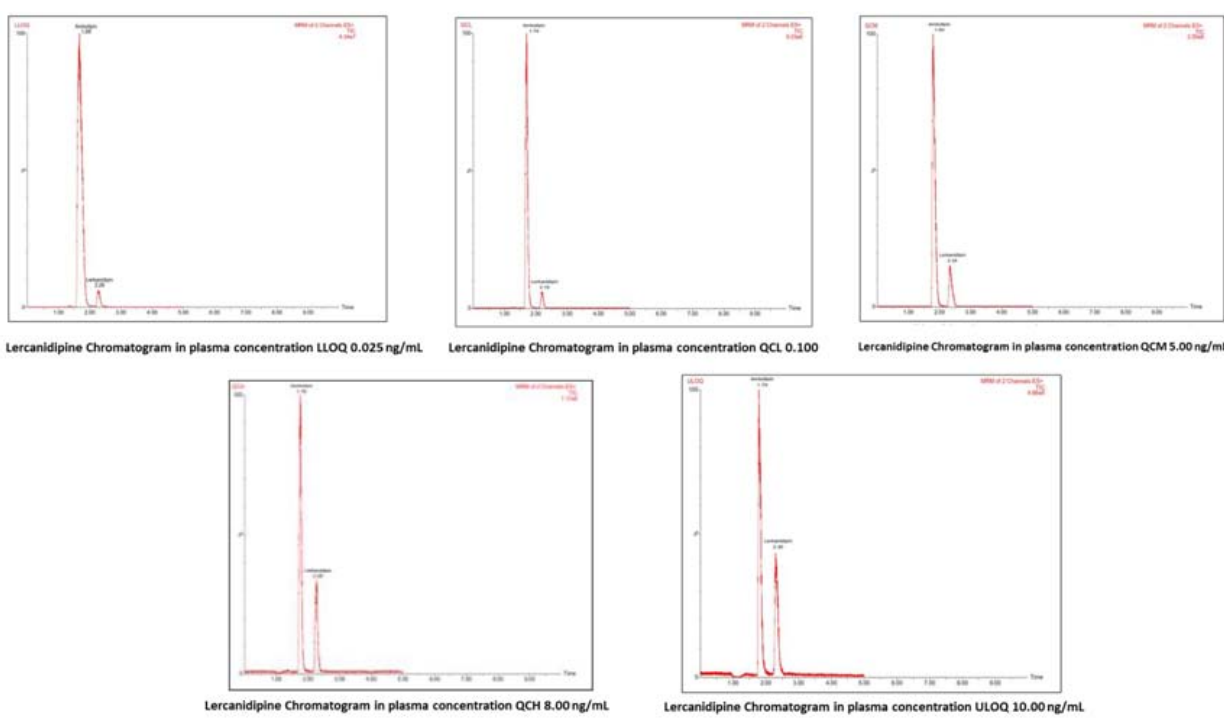

Fig. 2: Lercanidipine chromatogram in plasma with a concentration of LLOQ, QCL, QCM, QCH, and ULOQ 
Table 1: Data of carry over

\begin{tabular}{lll}
\hline Blank sample & Lercanidipine carry over (\%) & Internal standard carry over (\%) \\
\hline Blank 1 & 6.508 & 0.063 \\
Blank 2 & 10.954 & 0.078 \\
Blank 3 & 2.524 & 0.164 \\
Blank 4 & 11.996 & 0.071 \\
Blank 5 & 4.030 & 0.224 \\
Mean & $7.202 \pm 4.168$ & $0.120 \pm 0.071$ \\
\hline
\end{tabular}

$*$ Each value is represented as mean \pm SD

\section{Carryover}

The result showed that no carry over in plasma blanks after injection of the highest concentration (ULOQ) lercanidipine. The carryover percentage still meets the requirements for analytes $<20 \%$ and $<5 \%$ for the internal standard. The result can be seen in table 1.

\section{Calibration curve and LLOQ}

The calibration curve was linear in the concentration range of 0.025-10.0 $\mathrm{ng} / \mathrm{ml}$ with correlation coefficient $(\mathrm{r})>0.9986$. The LLOQ of lercanidipine was $0.025 \mathrm{ng} / \mathrm{ml}$ with $\mathrm{CV}$ of $9.32 \%$ and $\%$ diff between- $17.74 \%$ to $6.20 \%$.

\section{Accuracy, precision, and recovery}

This research performed accuracy and precision in within-run and between-run. The test was performed using five replicates on each of four concentrations of quality control samples, such as LLOQ $(0.025$ $\mathrm{ng} / \mathrm{ml})$; low concentration/QCL $(0.1 \mathrm{ng} / \mathrm{ml})$; medium concentration/
QCM (4.0 ng/ml); and high concentration/QCH $(8.0 \mathrm{ng} / \mathrm{ml})$ for each time of analysis (within-run) and performed as many as three times the analysis of at least 2 different days (between-run). Accuracy was made to see the proximity of the measured concentration results in the analysis with the actual concentration represented by the diff\% (bias) value, whereas the precision was performed to see the proximity between the repetitions of the measurement analytes represented by the $\%$ CV value. The method was accurate and precise because all values met the requirements that bias (\%diff) and CV for LLOQ not more than $20 \%$ while other concentration levels were not more than $15 \%$. The result can be seen in table 2 .

Besides accuracy and precision, recovery was conducted to know the extraction efficiency. The recovery was calculated by comparing the area of analyte obtained after extraction with the unextracted analytical area at the same concentration. Recovery of lercanidipine at three levels of concentration QCL, QCM, and QCL was $81.89-89.98 \%$

Table 2: Data of accuracy and precision

\begin{tabular}{|c|c|c|c|c|c|c|}
\hline Actual & Within-run & & & Between-run & & \\
\hline Conc (ng/ml) & Meas Conc (mean $\pm S D ; n g / m l)$ & CV (\%) & Bias (\%) & Meas Conc (mean $\pm S D ; n g / m l)$ & CV (\%) & Bias (\%) \\
\hline 0.025 & $0.023 \pm 0.001$ & 4.731 & -8.99 & $0.026 \pm 0.0029$ & 10.946 & 5.34 \\
\hline 0.100 & $0.102 \pm 0.004$ & 3.565 & 2.15 & $0.104 \pm 0.005$ & 5.245 & 4.34 \\
\hline 5.000 & $4.924 \pm 0.067$ & 1.366 & -1.52 & $4.929 \pm 0.247$ & 5.004 & -1.43 \\
\hline 8.000 & $7.747 \pm 0.201$ & 2.590 & -3.17 & $7.727 \pm 0.220$ & 2.848 & -3.41 \\
\hline
\end{tabular}

*Each value is represented as mean \pm SD of 5 replicates, CV: Coefficient of Variation

\section{Dilution integrity}

Dilution integrity was performed to ensure that dilutions during the analysis were accurate and reliable. The test was performed with a concentration above ULOQ or two QCH concentrations of $16 \mathrm{ng} / \mathrm{ml}$, diluted to half $(8 \mathrm{ng} / \mathrm{ml})$ and one quarter $(4 \mathrm{ng} / \mathrm{ml})$ using a plasma blank. The analysis was conducted in five replicates on each dilution within-run and between-run and the accuracy and precision parameters were observed. The result showed that until one quarter dilution, the CV and bias (\%diff) were not more than 15\%, 9.458\% (CV within-run) and $7.949 \%$ (CV between-run) with bias of $0.50 \%$ (withinrun) and $-0.63 \%$ (between-run) for half dilution, while for one quarter dilution the CV was $4.208 \%$ (within-run) and $4.137 \%$ (between-run) with bias of 5.21\% (within-run) and 3.42\% (between-run).

\section{Matrix effect}

Matrix effect was conducted because the analysis of lercanidipine in plasma using mass spectrometry. The matrix effect describes the presence of other compounds outside the analyte and internal standard in the ionization of the analyte and the internal standard in ionization process. This effect was represented by the matrix factor by calculating the percentage between the analyte area added after the blank extraction process with the standard solution area. The result can be seen in table 3 .

Table 3: Data of matrix effect of lercanidipine in plasma

\begin{tabular}{|c|c|c|c|c|}
\hline \multirow{2}{*}{$\begin{array}{l}\text { Actual Conc } \\
\text { (ng/ml) }\end{array}$} & \multirow{2}{*}{$\begin{array}{l}\text { Matrix factor matrix factor } \\
\text { (mean } \pm \text { SD; \%) }\end{array}$} & \multirow{2}{*}{$\begin{array}{l}\text { CV } \\
(\%)\end{array}$} & \multicolumn{2}{|l|}{ Internal standard normalized matrix factor } \\
\hline & & & Matrix factor (mean \pm SD; \%) & CV (\%) \\
\hline 0.100 & $84.19 \pm 3.64$ & 4.32 & $4.53 \pm 0.26$ & 5.68 \\
\hline 8.000 & $85.83 \pm 1.39$ & 1.62 & $4.62 \pm 0.28$ & 6.03 \\
\hline
\end{tabular}

*Each value is represented as mean $\pm \mathrm{SD}$ of 5 replicates CV: Coefficient of Variation

\section{Stability}

The stability test was carried out in order to ensure that the storage condition and sample preparation not affecting the concentration of the analyte. The stability test was performed using QCL and QCH samples of each of the three replicates. For short-term stability tests, samples were stored at room temperature for $24 \mathrm{~h}$.

The results showed that lercanidipine was stable in plasma for at least $24 \mathrm{~h}$ at room temperature. 
Table 4: Short-term stability of lercanidipine in plasma

\begin{tabular}{|c|c|c|c|c|c|c|}
\hline \multirow[t]{2}{*}{ Hour } & \multicolumn{2}{|l|}{ QCL 0.100ng/ml } & \multicolumn{4}{|c|}{ QCH 8.000 ng/ml } \\
\hline & Meas conc (mean $\pm S D ; n g / m l)$ & CV (\%) & Bias (\%) & Meas conc (mean $\pm S D ; n g / m l)$ & CV (\%) & Bias (\%) \\
\hline 0 hour & $0.096 \pm 0.005$ & 5.515 & -3.52 & $7.396 \pm 0.390$ & 5.272 & -7.55 \\
\hline 6 hour & $0.107 \pm 0.007$ & 6.438 & 7.36 & $7.714 \pm 0.273$ & 3.545 & -3.58 \\
\hline 12 hour & $0.109 \pm 0.003$ & 2.831 & 9.38 & $7.921 \pm 0.414$ & 5.230 & -0.99 \\
\hline
\end{tabular}

*Each value is represented as mean \pm SD of 3 replicates CV: Coefficient of Variation

The study also performed long-term stability tests, in which the sample was stored in a freezer temperature of $-20^{\circ} \mathrm{C}$ in the periods of $0,7,14 \mathrm{~d}$, freeze and thaw, thus post preparation stability (autosampler). The stability testing results showed that lercanidipine in plasma was stable for at least $14 \mathrm{~d}$ at- $20^{\circ} \mathrm{C}$, after freeze-thaw for at least three cycles, and was stable for at least $24 \mathrm{~h}$ in the autosampler.

The selected ionisation source in this research was ESI (Electrospray Ionization) type positive because the analyte and internal standard were basic therefore ionization can be done by addition of $\mathrm{H}^{+}$ion or protonation. The value of $\mathrm{m} / \mathrm{z}$ is based on the greatest abundance in each value. Lercanidipine was detected at an $\mathrm{m} / \mathrm{z}$ ratio of $612.18>280.27$ whereas amlodipine was detected at $409.1>238.15$. The acquired $\mathrm{m} / \mathrm{z}$ value was based on the greatest abundance in each value. Parent ion of lercanidipine was detected at $\mathrm{m} / \mathrm{z}$ value of 612.18 , then was fragmented into methyl-5-formyl-2,6-dimethyl-4-(3-nitrophenyl)-1,4- dihydro-pyridine-3-carboxylate at $\mathrm{m} / \mathrm{z}$ 315.0; (3.3-diphenylpropyl) (methyl)(2-methylprop-1-en-1-yl)amine at $\mathrm{m} / \mathrm{z}$ value 298.3; and 1-[(3,3diphenylpropyl) (methyl) amino]-2-methylpropan-2-ol at m/z 280.27 [7].

Parent ion of amlodipine 3-Ethyl-5-methyl-2-[(2-aminoethoxy) methyl]-4-(2-chlorophenyl)-6-methyl-1,4-dihydropyridine-3,5dicarboxylic acid at $\mathrm{m} / \mathrm{z}$ value 409.1 . Then this parent fragmented into a 3-Ethyl-5-methyl-4-(2-chlorophenyl)-2-(ethoxymethyl)-6-methyl-1, 4-dihydropyridine-3,5-dicarboxylic acid at $\mathrm{m} / \mathrm{z}$ value 377.20 ; ethyl (2E)-3-amino-2-[(2-chlorophenyl) methyl]-4-(ethenyloxy) but-2enoate at $\mathrm{m} / \mathrm{z}$ value of 294.14 ; and ethyl (2E)-3-amino-2-[(2chlorophenyl) methyl] prop-2-enoate at an $\mathrm{m} / \mathrm{z}$ value of 238.15 [8]. The mass spectrum of each fragmentation can be seen in fig. 3 and fig. 4. The selected ionization source was ESI (Electrospray Ionization) positive type.

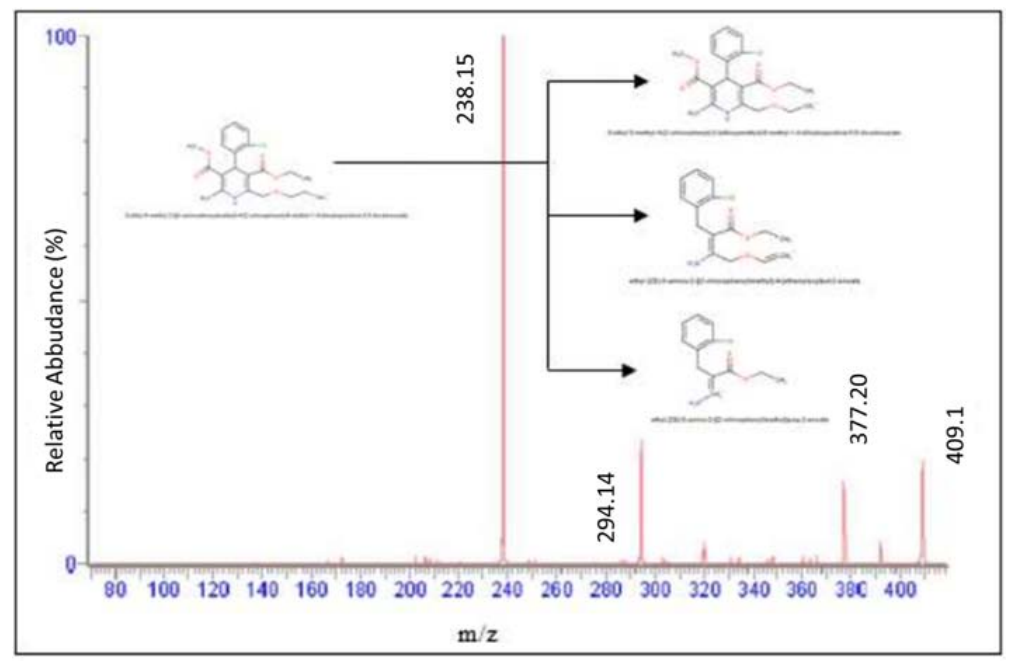

Fig. 3: Lercanidipine mass spectrum and ion fragmentation

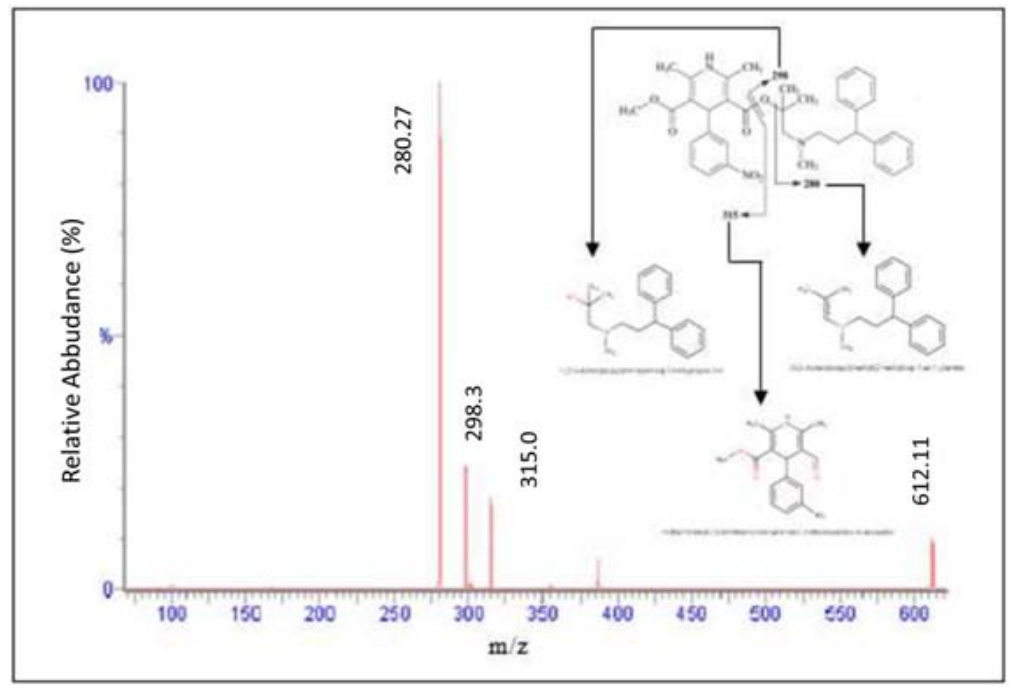

Fig. 4: Amlodipine mass spectrum and ion fragmentation 
Sample preparation was conducted using liquid-liquid extraction. This method was chosen because it cleans the analytes of many impurities in the plasma and can extend the life of the column because the impurity compound retained in the column becomes less. The parameters observed were the area of the resulting analyte and the best chromatogram peak. The optimization was carried out by some solvents i.e. n-hexane, ethyl acetate, a combination of nhexane-ethyl acetate (50:50), and dichloromethane with the addition of 10 times the plasma amount each. Consideration of using such organic solvents as extracting solutions because they are non-polar and the analyte also non-polar so that the analyte will be extracted into the organic phase (separate from the proteins in the plasma). The optimization results were selected based on the analytical area and the internal standard and chromatogram form of each compound. The optimum condition was obtained by the extraction method using a combination of n-hexane and ethyl acetate (50:50) as a solvent with a good chromatogram in each compound. After the optimum extracting solution was obtained, the optimization of vortex mixed and centrifugation was performed. Optimizations were conducted for 1, 2, and 3 min and vortexed for 5, 10, 15, and $20 \mathrm{~min}$ for centrifugation. The optimum condition was obtained on vortex mixed for $3 \mathrm{~min}$ and $20 \mathrm{~min}$ of centrifugation time as it produced the largest area, while the optimum time for evaporation of the organic solvent was $30 \mathrm{~min}$. Based on all value results of validation that met the requirements of EMA Guideline on Bioanalytical Method Validation, 2011, it can be concluded that the developed method was valid. In this study, LLOQ was obtained up to $0.05 \mathrm{ng} / \mathrm{ml}$, more specific than previous research. In addition, the sample preparation in this study was carried out by liquid-liquid extraction which was more economical.

\section{CONCLUSION}

The developed method was valid and linear in the range concentration of $0.025-10 \mathrm{ng} / \mathrm{ml}$ and can be applied in pharmacokinetic and bioequivalence studies.

\section{AUTHORS CONTRIBUTIONS}

All the authors have contributed equally

\section{CONFLICT OF INTERESTS}

Declared none

\section{REFERENCES}

1. McClellan KJ, Jarvis B. Lercanidipine: a review of its use in hypertension. Adis Drug Evaluation; 2000. p. 1123-40.

2. Food and Drug Supervisory Agency of the Republic of Indonesia. Regulation of the Head of the National Agency of Drug and Food Control of the Republic of Indonesia Number HK.03.1.23.12.11.10217 Y 2011 on Drugs that are compulsory to take the equivalent test; 2011.

3. European Medicines Agency: Committee for Medicinal Products for Human Use (CHMP). Guideline on Bioanalytical Method Validation. London: European Medicines Agency; 2011.

4. Chaudhary DV, Patel DP, Shah PA, Shah JV, Sanyal M, Shrivastav PS. Determination of lercanidipine in human plasma by an improved UPLC-MS/MS method for a bioequivalence study. J Pharm Anal 2015;1-8. Doi:10.1016/j.jpha.2015.09.001

5. Younes KM, El Kady EF. A new validated bio-analytical liquid chromatographic-tandem mass spectrometric method for the quantification of lercanidipine in human plasma. Intl J Anal Bio Chem 2013;3:169-77.

6. Jabor V, Coelho E, Ifa D, Bonato $P$, Santos N, Lanchote V. Enantioselective determination of lercanidipine in human plasma for pharmacokinetic studies by normal-phase liquid-chromatographytandem mass spectrometry. J Chromatogr B 2003;796:429-37.

7. Kalovidouris M, Michaela S, Robola N, Koutsopoulou M, Panderi I. Ultra performance liquid chromatography/tandem mass spectrometry method for determination of lercanidipine in human plasma. Rapid Commun Mass Spectrom 2006;20:2939-46.

8. Tiwari NR, Shah N, Bhalani V, Mahajan A. LC, MS, and LCMS/MS studies for characterization of degradation products of amlodipine. J Pharm Anal 2015;5:33-42. 